\title{
The Impact of Extreme Maternal Ages on Hypertensive Disorders of Pregnancy: A Retrospective Cohort Study in Dakar, Senegal
}

\author{
Mame Diarra Ndiaye ${ }^{1,2 *}$, Mamour Gueye ${ }^{1,2}$, Moussa Diallo', Mouhamadou Wade ${ }^{1,2}$, \\ Abdoulaye Diakhate ${ }^{1,2}$, Aliou Diouf ${ }^{1,2}$, Ndama Niang1,2, Simon Birame Ndour,, \\ Ndeye Gothe Fall ${ }^{1,2}$, Magatte Mbaye ${ }^{2}$, Jean Charles Moreau ${ }^{1}$
${ }^{1}$ Gynecologic and Obstetric Clinic, Aristide Le Dantec Teaching Hospital, Cheikh Anta Diop University, Dakar, Senegal ${ }^{2}$ Philippe Senghor Health Center, Cheikh Anta Diop University, Dakar, Senegal \\ Email: *diarryatoundiayegueye@gmail.com
}

How to cite this paper: Ndiaye, M.D., Gueye, M., Diallo, M., Wade, M., Diakhate, A., Diouf, A., Niang, N., Ndour, S.B., Fall, N.G., Mbaye, M. and Moreau, J.C. (2020) The Impact of Extreme Maternal Ages on Hypertensive Disorders of Pregnancy: A Retrospective Cohort Study in Dakar, Senegal. Open Journal of Obstetrics and $G y$ necology, 10, 213-220.

https://doi.org/10.4236/ojog.2020.1020018

Received: January 2, 2020

Accepted: February 3, 2020

Published: February 6, 2020

Copyright $\odot 2020$ by author(s) and Scientific Research Publishing Inc. This work is licensed under the Creative Commons Attribution International License (CC BY 4.0).

http://creativecommons.org/licenses/by/4.0/ (c) (i) Open Access

\begin{abstract}
Background: Hypertensive disorders of pregnancy are a frequent situation and involve about $8 \%-10 \%$ of pregnancies. Extremes maternal ages have been associated to hypertensive disorders of pregnancy. In Africa, even if motherhood in teens is common, pregnancy at advanced age is getting more and more frequent. Objectives: To investigate the relation between maternal age and hypertensive disorders of pregnancy. Methods: A retrospective cohort study over 8 years was conducted in a suburb setting in Dakar, Senegal. The participants were divided into two groups based on the occurrence of hypertensive disorders of pregnancy (HDP). Data were extracted from E-Perinatal, our electronic medical recording system and analyzed using SPSS 20.0 and R Studio software version 1.1.383.51. Maternal and perinatal outcomes were assessed over 3 age groups: $<19$ years, $>34$ years and $19-34$ years old. Results: The study included 2226 cases of HDP out of 36,499 deliveries leading to an incidence of $6.1 \%$. The proportions of nulliparous, multiple pregnancies and maternal diabetes were higher in women with HDP. The risk of high blood pressure among mothers aged 35 years and over was 1.6 times as high as the risk among those aged 19 - 34 years at a significant level before and after adjusting for third factors i.e. parity, multiple pregnancy and diabetes. However, adolescents were found to have the same risk compared to their counterparts aged 19 - 34 years. Risk of eclampsia was 4 times greater among adolescent girls. Conclusion: Advanced maternal age greater than or equal to 35 years is a risk factor for high blood pressure. There is no extra risk in adolescent girls with regard to high blood pressure; however, risk of eclampsia was higher in this group.
\end{abstract}




\section{Keywords}

Hypertensive Disorders of Pregnancy, Age, Perinatal Outcome

\section{Introduction}

Up to $8 \%$ of pregnant women suffer from Hypertensive disorders of pregnancy (HDP) [1]. In Africa, the rate of HDP is $4 \%$ in the general population [1] and can rise up to $16 \%$ in hospital based studies [2]. HDP is the second leading cause of maternal death [3]. Teen and advanced maternal age (age $\geq 35$ ) pregnancies are both at increased risk for maternal and neonatal complications including hypertensive disorders [4] [5].

The average age at childbirth is increasing worldwide and more and more women give birth after age 35 or even 40 [4]. Although teen pregnancies are rare in some countries [6], each year, 16 million adolescent girls aged $15-19$ give birth in the world comprising 2.5 million under 16 in developing countries [7] [8]. In Senegal and in other African countries, even if motherhood in teens is common, pregnancy at advanced age is getting more and more frequent.

HDP lead to acute life-threatening complications occurring during pregnancy, childbirth or during the postpartum. These obstetric complications are the leading causes of death for girls aged 15 - 19 [9].

This paper is aimed at investigating the relationship between maternal age and HDP in Dakar, Senegal.

\section{Methods}

\subsection{Setting and Study Population}

A retrospective cohort study over 8 years was conducted from January 2012 to December 2018 at Philippe Maguilen Senghor (PMS) health center in Dakar, Senegal. All mothers who delivered at PMS during the study period were identified from E-Perinatal, an Electronic Medical Recording system, and assessed for eligibility for recruitment. Inclusion criteria comprised patients which had delivered at PMS with hypertensive disorders including preeclampsia (and related acute outcomes such as eclampsia), gestational hypertension and chronic hypertension [10]. Preeclampsia refers to as the occurrence in pregnant women, after 20 weeks of gestation, of high blood pressure greater than or equal to 140/90 $\mathrm{mmHg}$ associated with proteinuria greater than or equal to $300 \mathrm{mg} / 24$ hours. Proteinuria could also be defined as a dipstick measurement of at least $2+$. Chronic hypertension was defined as hypertension present prior to pregnancy or that is diagnosed before 20 weeks of gestation. Gestational hypertension was defined as having a blood pressure higher than $140 / 90 \mathrm{~mm} \mathrm{Hg}$ without the presence of protein in the urine and diagnosed after 20 weeks of gestation.

Exclusion criteria included mothers with incomplete files especially when maternal age was not specified. 
Patients without hypertensive disorders of pregnancy who had delivered at PMS during the study period were considered as controls. No matching was conducted.

\subsection{Outcomes}

Maternal and neonatal outcomes were described by maternal age, type of pregnancy, maternal and fetal adverse outcomes of hypertensive disorders (abruptio placentae, eclampsia, HELLP syndrome, small for gestational age and stillbirth). Furthermore, age was categorized in 3 groups: $<19$ years old, $\geq 35$ years old and 19 - 35 years old. The latter was the reference group.

\subsection{Data Analysis}

Data were extracted from E-Perinatal, our electronic medical recording system and analyzed using SPSS 20.0 and R Studio software version 1.1.383.51.

Mean, median and standard deviation were considered to describe continuous variables while frequencies were reported for categorical and nominal variables. Differences between categorical variables were assessed using chi-squared test at a significance level of $\mathrm{p}<0.05 \%$ while Student's t-test was used to assess continuous variables. We sought for an association between predictive variables and the hypertensive disorders. Then, we considered the possible confounders or effect modifiers by a stratified analysis using Woolf test. In case of confounding factor, the adjusted risk of Mantel Haenszel was used. We also carried out a multiple logistic regression considering, in addition to maternal age, other parameters associated with hypertensive disorders.

\section{Results}

The study included 2226 cases of HDP out of 36,513 deliveries leading to an incidence of $6.1 \%$. The control group was made of 34,287 mothers without hypertensive disorders of pregnancy. The average patients' age was 27.4 years with a median of 27 years (range 13 - 53 years). Women $<19$ years old and those $\geq 35$ years old accounted for $6.5 \%$ and $15 \%$ respectively.

Table 1 shows characteristics of study participants. Women with hypertensive disorder were older on average. The incidence of nulliparous women, that of multiple pregnancies and of diabetes were higher in women with hypertensive disorders of pregnancy.

The risk of high blood pressure among mothers aged 35 years and over was 1.6 times as high as the risk among those aged 19 - 34 years at a significant level as shown in Table 2. However, adolescents were found to have the same risk compared to their counterparts aged 19 - 34 years.

The risk of eclampsia amongst adolescents was 4 times as high as the risk of eclampsia among patients aged 19 to 34 years $(\mathrm{OR}=4.0,2.8-5.5, \mathrm{p}<0.001)$. On the other hand, advanced maternalage was a protective factor for eclampsia (OR $=0.4,0.2-0.7, \mathrm{p}<0.001)$ with a significantly lower risk of $60 \%$. 
Table 1. Study population characteristics.

\begin{tabular}{cccc}
\hline & Mean & Number (\%) & p \\
\hline & Age & & \\
Hypertensive disorders of pregnancy & 28.4 & - & $<0.001$ \\
No hypertensive disorders of pregnancy & 27.3 & & \\
Nulliparous & $980(44.0)$ & \\
Hypertensive disorders of pregnancy & $13,275(36.4)$ & $<0.001$ \\
No hypertensive disorders of pregnancy & & \\
Twin pregnancy & $121(5.4)$ & $<0.001$ \\
Hypertensive disorders of pregnancy & $973(2.8)$ & \\
No hypertensive disorders of pregnancy & & $108(4.9)$ & \\
Hypertensive disorders of pregnancy & Diabetes & $652(1.9)$ & $<0.001$ \\
No hypertensive disorders of pregnancy & & \\
\hline
\end{tabular}

Table 2. Relation between maternal age and Hypertensive disorders of pregnancy.

\begin{tabular}{|c|c|c|c|c|}
\hline \multicolumn{5}{|c|}{ Hypertensive disorders } \\
\hline & Yes & No & $\mathrm{RR}\left[{ }_{95 \%} \mathrm{CI}\right]$ & $\mathrm{p}$ \\
\hline \multicolumn{5}{|c|}{ High blood pressure } \\
\hline 18 - 34 years & $1600(5.6)$ & $27,070(94.4)$ & & \\
\hline$<18$ years & $136(5.7)$ & $2248(94.3)$ & $1.0[0.9 ; 1.2]$ & 0.80 \\
\hline$\geq 35$ years & $490(9.0)$ & $4969(91.0)$ & $1.6[1.5 ; 1.8]$ & $<0.001$ \\
\hline \multicolumn{5}{|c|}{ Abruptio placentae } \\
\hline $18-34$ years & $389(24.7)$ & $1188(75.3)$ & - & \\
\hline$<18$ years & $26(17.6)$ & $122(82.4)$ & $0.7[0.5 ; 1.0]$ & 0.06 \\
\hline$\geq 35$ years & $115(22.9)$ & $383(77.1)$ & $0.9[0.8 ; 1.1]$ & 0.47 \\
\hline \multicolumn{5}{|c|}{ Eclampsia } \\
\hline 18 - 34 years & $99(6.7)$ & $1477(93.3)$ & & \\
\hline$<18$ years & $37(22.8)$ & $112(77.2)$ & $4.0[2.8 ; 5.5]$ & $<0.001$ \\
\hline$\geq 35$ years & $13(2.6)$ & $488(97.4)$ & $0.4[0.2 ; 0.7]$ & 0.001 \\
\hline \multicolumn{5}{|c|}{${ }^{c}$ HELLP Syndrome } \\
\hline 18 - 34 years & $11(0.6)$ & $1570(99.4)$ & & \\
\hline$<18$ years & $0(0.0)$ & $144(100)$ & $0.5[0.1 ; 8.0]$ & 0.605 \\
\hline$\geq 35$ years & $5(1.0)$ & $496(99.0)$ & $1.4[0.5 ; 4.1]$ & 0.501 \\
\hline \multicolumn{5}{|c|}{ Fetal growth retardation } \\
\hline $18-34$ years & $105(6.7)$ & $1471(93.3)$ & & \\
\hline$<18$ years & $5(3.3)$ & $144(92.7)$ & $0.4[0.2 ; 1.2]$ & 0.11 \\
\hline$\geq 35$ years & $23(4.7)$ & $463(95.3)$ & $0.7[0.4 ; 1.1]$ & 0.12 \\
\hline \multicolumn{5}{|c|}{ Preterm birth } \\
\hline 18 - 34 years & $361(22.3)$ & $1254(77.7)$ & & \\
\hline$<18$ years & $29(19.2)$ & $122(80.8)$ & $0.9[0.6 ; 1.2]$ & 0.41 \\
\hline$\geq 35$ years & $106(21.0)$ & $399(79.0)$ & $0.9[0.8 ; 1.1]$ & 0.57 \\
\hline
\end{tabular}

${ }^{a} \mathrm{RR}=$ Relative risk, ${ }_{95 \%} \mathrm{CI}=95 \%$ confidence interval, HELLP Syndrome $=$ Hemolysis Elevated Liver Enzymes Low platelets count. 
Table 3. Multiple logistic regression in women of $\geq 35$ years old for age, parity, multiple pregnancy and diabetes.

\begin{tabular}{ccccc}
\hline & Estimation $\beta$ & ${ }^{\mathrm{a}} \mathrm{RR}$ & ${ }^{\mathrm{b}} \mathrm{IC95 \%}$ & $\mathbf{p}$ \\
\hline Intercept & -3.5 & - & & \\
Age & 0.72 & 2.01 & {$[1.80 ; 2.33]$} & $<0.001$ \\
Primiparous & 0.54 & 1.68 & {$[1.54 ; 1.91]$} & $<0.001$ \\
Multiple pregnancy & 0.93 & 2.46 & {$[2.05 ; 3.13]$} & $<0.001$ \\
Diabetes & 1.23 & 3.32 & {$[2.75 ; 4.26]$} & $<0.001$ \\
Age: parity & -0.05 & 0.95 & {$[0.70 ; 1.28]$} & 0.74 \\
\hline
\end{tabular}

${ }^{\mathrm{a}} \mathrm{RR}=$ Relative risk, ${ }_{95 \%} \mathrm{CI}=95 \%$ confidence interval.

Table 4. Multivariate analysis of age and eclampsia adjusted to parity.

\begin{tabular}{|c|c|c|c|c|c|}
\hline \multicolumn{6}{|c|}{ Eclampsia } \\
\hline & $\begin{array}{c}\text { Yes } \\
\text { n (\%) }\end{array}$ & $\begin{array}{c}\text { No } \\
\text { n (\%) }\end{array}$ & ${ }^{\mathrm{a}} \mathbf{R} \mathbf{R}$ & $95 \% \mathrm{CI}$ & $\mathrm{p}$ \\
\hline \multicolumn{6}{|l|}{ Multiparous } \\
\hline 18 - 34 years & $48(5.9)$ & $755(94.1)$ & - & - & - \\
\hline$<18$ years & $4(30.8 \%)$ & $9(69.2 \%)$ & 5.2 & {$[2.2 ; 12.2]$} & 0.0002 \\
\hline$\geq 35$ years & $10(2.3)$ & 418 (97.7) & 0.4 & {$[0.2 ; 0.8]$} & 0.008 \\
\hline \multicolumn{6}{|l|}{ Nulliparous } \\
\hline $18-34$ years & $59(7.5)$ & $721(92.1)$ & - & - & - \\
\hline$<18$ years & $26(20.0)$ & $104(78.5)$ & 2.7 & {$[1.7 ; 4.0]$} & $<0.0001$ \\
\hline$\geq 35$ years & $2(2.9)$ & $70(97.1)$ & 0.4 & {$[0.1 ; 1.5]$} & 0.1573 \\
\hline
\end{tabular}

${ }^{\mathrm{a}} \mathrm{RR}=$ Relative risk, $95 \% \mathrm{CI}=95 \%$ confidence interval.

Abruptio placentae, fetal growth retardation, HELLP syndrome and premature birth did not differ between groups as shown in Table 2.

The association between advanced maternal age and high blood pressure remains positive after a multiple regression analysis adjusting age to parity, number of fetuses and diabetes as shown in Table 3. Parity was not a confounding factor.

However, parity was a factor modifying the effect in the association between age and eclampsia. Multiparous $<19$ years old had a significantly higher risk of eclampsia than nulliparous counterparts: $R R=5.20,2.2-12.3 p=0.0002$ versus $\mathrm{RR}=2.7,1.7-4.0, \mathrm{p}=0.0001)$ as shown in Table 4 .

\section{Discussion}

Our main findings are the association between advanced maternal age and hypertensive disorders of pregnancy and the relation between eclampsia and age under 19.

The average maternal age of patients was significantly higher in cases compared 
to controls. In contrast to our findings, Merviel et al. reported an insignificant difference in average age: 28.6 years in the preeclampsia group and 28.5 years in the control group. However, their sample considered only 188 cases [11].

A relation between maternal age and hypertensive disorders of pregnancy found in this study was consistent with that of Jacobsson of more than 1.5 million deliveries where a positive association between hypertension and severe preeclampsia in women over 40 was noted [12].

After adjustment for parity, multiple pregnancy and maternal diabetes, the association between advanced age and hypertensive disorders of pregnancy remains: adjusted $\mathrm{OR}=2.01,95 \% \mathrm{CI}=[1.80 ; 2.33], \mathrm{p}<0.001$. Although primiparity is known as a risk factor for high blood pressure during pregnancy in our study, it does not modify the effect of age on the onset of hypertensive disorders. In addition, Moaddab et al. reported an adjusted RR greater than or equal to 1.26 for maternal and neonatal outcomes in woman undergoing in vitro fertilization over 40 years [13].

Wennberg et al. investigated the risk of perinatal complications after assisted reproductive technology (ART) compared to spontaneous conception, and found a significant risk of high blood pressure in women aged 25 years of 1.42 compared to the spontaneous conception group and a protective effect in those aged over 40 years [10]. However, cases of egg donation, particularly more frequent over 40 years of age, were not considered as third factors. In both cases, adjustment to multiple pregnancies, which is particularly frequent in ART, was not made.

Regarding teen mothers, no significant relationship with hypertensive disorders of pregnancy was found. The incidence in our study was similar to that of Wemaux-Denis et al. (6.9\% under 16 years of age and $7.5 \%$ in women aged between 16 and 17 years) [14]. The authors did not find any difference between these 2 groups.

The pathophysiology of preeclampsia associates a defect in trophoblastic invasion, placental hypoxia, oxidative stress as well as dysfunction of the maternal endothelium linked to various substances released by the placenta in the maternal circulation [15]. It is possible to hypothesise that these condition simply suggest the involvement of multiple risk factors in this process including the quality of the embryo which is strongly correlated with patient's age [16] [17].

These findings may help to understand the association between hypertensive disorders of pregnancy and advanced age.

One of the most important clinically relevant finding was the relation between eclampsia and age under 19. In accordance with the present results, previous studies have demonstrated similar findings. Moaddab et al., after adjusting for parity, found a risk that increases with maternal age: $\mathrm{RR}=1.26(\mathrm{CI} 95 \%=1.19$ 1.31) between 40 and 44 years, $\mathrm{RR}=1.55$ (CI $95 \%=1.45-1.67)$ between 44 and 49 years and $\mathrm{RR}=1.70(95 \% \mathrm{CI}=1.74-1.97)$ in women over 50 [13].

A strength of our study is that it was based on a large dataset of over 35,000 deliveries that occurred over 8 years. It therefore provides a clear insight of Da- 
kar's population. Data collection is reliable because the recording is continuous and does not only consider the variables included in the study, but a large number of demographics, obstetrical and neonatal characteristics. This increases the power to detect the association between exposure and outcomes assessed. Our results therefore can be generalized to other women who deliver in similar settings in Senegal. The identified maternal outcome associated with maternal age agrees with other studies.

However, the data in our study comes from medical records and some details of management as well as complications encountered may be missing.

\section{Conclusions}

Advanced maternal age was found in this study to be a risk factor for hypertensive disorders adjusted for primiparity, multiple pregnancy and diabetes.

Our findings suggest mothers at age risk to carry out ultrasound screening in the first trimester with the Doppler of the uterine arteries in order to better organize follow-up. We have not shown a higher risk of high blood pressure in teen mothers; however, they were more likely to suffer from eclampsia.

These results suggest a contribution of the quality of the egg in the defect of trophoblastic invasion.

\section{Conflicts of Interest}

The authors declare no conflicts of interest regarding the publication of this paper.

\section{References}

[1] Winer, N. and Tsasaris, V. (2008) Etude des connaissances: Prise en charge thérapeutique de la prééclampsie. Journal de Gynécologie Obstétrique et Biologie de la Reproduction, 37, 5-15. https://doi.org/10.1016/j.jgyn.2007.09.008

[2] Walle, T.A. and Azagew, A.W. (2017) Hypertensive Disorder of Pregnancy Prevalence and Associated Factors among Pregnant Women Attending Ante Natal Care at Gondar Town Health Institutions, North West Ethiopia 2017. Pregnancy Hypertension, 16, 79-84. https://doi.org/10.1016/j.preghy.2019.03.007

[3] Say, L., et al. (2014) Global Causes of Maternal Death: A WHO Systematic Analysis. The Lancet Global Health, 2, e323-e333. https://doi.org/10.1016/S2214-109X(14)70227-X

[4] Walker, K.F. and Thornton, J.G. (2016) Advanced Maternal Age. Obstetrics, Gynaecology and Reproductive Medicine, 26, 354-357. https://doi.org/10.1016/j.ogrm.2016.09.005

[5] Iloki, L.-H., Koubaka, R., Itoua, C. and Mbemba Moutounou, G.-M. (2004) Grossesse et accouchement chez l'adolescente au Congo: A propos de 276 cas au CHU de Brazzaville. Journal de Gynécologie Obstétrique et Biologie de la Reproduction, 33, 37-42. https://doi.org/10.1016/S0368-2315(04)96310-7

[6] Lavin, C. and Cox, J.E. (2012) Teen Pregnancy Prevention: Current Perspectives. Current Opinion in Pediatrics, 24, 462-469.

https://doi.org/10.1097/MOP.0b013e3283555bee 
[7] Neal, S., Matthews, Z. and Frost, M.H. (2012) Childbearing in Adolescents Aged 12-15 Years in Low Resource Countries: A Neglected Issue. New Estimates from Demographic and Household Surveys in 42 Countries. Acta Obstetricia et Gynecologica Scandinavica, 91, 1114-1118. https://doi.org/10.1111/j.1600-0412.2012.01467.x

[8] UNFPA (2015) Girlhood, Not Motherhood: Preventing Adolescent Pregnancy. UNFPA, New York.

[9] WHO (2016) Global Health Estimates 2015: Deaths by Cause, Age, Sex, by Country and by Region, 2000-2015. WHO, Geneva.

[10] Wennberg, A.L., et al. (2016) Effect of Maternal Age on Maternal and Neonatal Outcomes after Assisted Reproductive Technology. Fertility and Sterility, 106, 1142-1149.e14. https://doi.org/10.1016/j.fertnstert.2016.06.021

[11] Merviel, P., et al. (2008) Facteurs de risque de la prééclampsie en cas de grossesse unique. Journal de Gynécologie Obstétrique et Biologie de la Reproduction, 37, 477-482. https://doi.org/10.1016/j.jgyn.2008.04.001

[12] Jacobsson, B., Ladfors, L. and Milsom, I. (2004) Advanced Maternal Age and Adverse Perinatal Outcome. Obstetrics \& Gynecology, 104, 727-733. https://doi.org/10.1097/01.AOG.0000140682.63746.be

[13] Moaddab, A., et al. (2017) Effect of Advanced Maternal Age on Maternal and Neonatal Outcomes in Assisted Reproductive Technology Pregnancies. European Journal of Obstetrics \& Gynecology and Reproductive Biology, 216, 178-183. https://doi.org/10.1016/j.ejogrb.2017.07.029

[14] Wemaux-Denis, C., et al. (2017) Grossesse et accouchement de l'adolescente: Le pronostic obstétrical est-il plus défavorable entre 13 et 15 ans? Gynécologie Obstétrique Fertilité \& Sénologie, 45, 5-8. https://doi.org/10.1016/j.gofs.2016.12.007

[15] Tsatsaris, V., Fournier, T. and Winer, N. (2008) Physiopathologie de la prééclampsie. Journal de Gynécologie Obstétrique et Biologie de la Reproduction, 37, 16-23. https://doi.org/10.1016/j.jgyn.2007.08.003

[16] Duport Percier, M., Anahory, T., Ranisavljevic, N. and Bringer-Deutsch, S. (2017) Mauvaises répondeuses: Peut-on améliorer nos résultats? Gynécologie Obstétrique Fertilité \& Sénologie, 45, 95-103. https://doi.org/10.1016/j.gofs.2016.12.023

[17] Cabry, R., et al. (2014) Management of Infertility in Women over 40. Maturitas, 78, 17-21. https://doi.org/10.1016/j.maturitas.2014.02.014 